Referencia para citar este artículo: De Martino-Bermúdez, M. \& López, F. (2017). Jóvenes que no estudian ni trabajan en Uruguay. La experiencia del Programa Jóvenes en Red. Revista Latinoamericana de Ciencias Sociales, Niñez y Juventud, 15 (2), pp. 861-876. DOI:10.11600/1692715x.1520502032015.

\title{
Jóvenes que no estudian ni trabajan en Uruguay. La experiencia del Programa Jóvenes en Red*
}

\author{
Mónica De Martino-BERMÚdeZ \\ Profesora Universidad de la República, Uruguay. \\ FERNANDO LÓPEZ ${ }^{* * *}$ \\ Técnico Ministerio de Desarrollo Social, Uruguay.
}

\section{Artículo recibido en marzo 2 de 2015; artículo aceptado en agosto 8 de 2016 (Eds.)}

- Resumen (analítico): la situación de los jóvenes y las jóvenes "ni-ni" ha tomado cierta relevancia en Uruguay a partir de los resultados del sistema de educación formal y los impactos del desempleo en la juventud. Inserto en este campo temático, el presente trabajo parte de la sistematización de una práctica profesional en el Programa Jóvenes en Red, dependiente del Ministerio de Desarrollo Social, con un doble objetivo: por un lado, colectivizar las formas de intervención desarrolladas para aportar al trabajo con la juventud; por otro lado, analizar las construcciones simbólicas de estos jóvenes y estas jóvenes en torno a su propia condición. Esto arrojó al menos tres cuestiones a las que este artículo se dedica: las dificultades de objetivación, la dosis de angustia no canalizada y la fuerte domesticidad psicosocial que caracteriza a esta población.

Palabras clave: juventud, estudio, trabajo, exclusión, Uruguay (Tesauro Unesco-Isis).

\section{Young people who not in employment, education or training (Neet) in Uruguay. The experience of the Youth in Network Program}

- Abstract (analytical): the situation of young people who neither work nor study has become more significant in Uruguay due to the results from the formal education system and the subsequent impact on youth unemployment. Focused on this issue, this study is a systematization of professional practice carried out in the Youth in Network Program developed by the Ministry of Social Development. This process has two objectives: firstly, to share the interventions that were designed and implemented as a contribution to working with young people. The purpose is to analyze the symbolic constructions of these young people about their own condition. During the research process three topics emerged

Este artículo de reflexión se enmarca en el Área de Conocimiento: Otras Ciencias Sociales, Subárea: Interdisciplinaria. Es una síntesis de la sistematización de la experiencia profesional desarrollada por el Lic. Fernando López en el marco del Diploma de Especialización en Intervención Familiar, coordinado por la Dra. Mónica De Martino-Bermúdez, perteneciente al Departamento de Trabajo Social de la Facultad de Ciencias Sociales-Universidad de la República. Fue presentada a los efectos de acceder al título de Diplomado en Intervenciones Familiares. La sistematización incluye el trabajo de campo realizado por el Lic. Fernando López en el marco del Ministerio de Desarrollo Social a lo largo del año lectivo 2013: 15 de Marzo 2013-30 de noviembre 2013. Tales elaboraciones se presentan ahora desde una perspectiva psicosocial a partir de la elaboración conjunta de ambos autores.

** Profesora Titular en Régimen de Dedicación Total del Departamento de Trabajo Social de la Facultad de Ciencias Sociales de la Universidad de la República. Asistente Social y Socióloga. Doctora en Ciencias Sociales por la Universidad Estatal de Campinas-Unicamp-Brasil Docente y Coordinadora del Diploma de Especialización en Intervención Familiar del mencionado Departamento. Investigadora Nivel II del Sistema Nacional de Investigadores. Docente invitada en el Doctorado en Ciencias Sociales de la Universidad de Buenos Aires. Orcid: 0000-0002-15866531. Índice H5: 10. Correo electrónico: monica.demartino@cienciassociales.edu.uy

*** Psicólogo. Diplomado en Intervención Familiar por el Departamento de Trabajo Social de la Facultad de Ciencias Sociales de la Universidad de la República. Técnico del Programa Jóvenes en Red del Instituto Nacional de la Juventud-Ministerio de Desarrollo Social. Orcid: 000000034919 2229. Correo electrónico: fernandolopez5005@hotmail.com 
that are discussed in this article: the difficulties of objectifying this population, the levels of unresolved anxiety that these young people face and the strong psycho-social domesticity that characterizes this population.

Key words: youth, study, work, exclusion, Uruguay (Thesaurus Unesco-Isis).

\section{Os jovens que não trabalham nem estudam no Uruguai. A experiência do Programa Jovens em Rede}

- $\quad$ Resumo (analítico): a situação dos jovens que não trabalham nem estudam atingiu certa relevância no Uruguai a partir dos resultados do sistema de educação formal e dos impactos do desemprego nos jovens. Dentro desta área temática, este trabalho têm como ponto inicial a sistematização de uma prática profissional no Programa Jovens em Rede do Ministério do Desenvolvimento Social, com dois objectivos: em primeiro lugar coletivizar as formas de intervenção desenvolvidas para trabalhar com juventude. Por outro lado, analisar as construções simbólicas desses jovens sobre a sua própria condição. O trabalho rendeu pelo menos três questões que o artigo debate : as dificuldades de objetivação, a dose de ansiedade não canalizada e a forte domesticidade psico - social que caracteriza esta população.

Palavras-chave: juventude, estudo, trabalho, exclusão, Uruguai (Thesaurus-Unesco Isis).

-1. Introducción. -2. El dominio empírico del trabajo. -3. La estrategia metodológica y las técnicas aplicadas. -4. Breves consideraciones teóricas. -5. Análisis del material recogido por cada técnica aplicada. $\mathbf{- 6}$. Reflexiones finales. -Lista de referencias.

\section{Introducción}

Convengamos que Uruguay es reconocido en la región por un sistema de protección social y una legislación considerada de avanzada respecto a un elenco amplio de derechos. Sumado a ello, su alto crecimiento económico en las últimas décadas y la tasa de desempleo más baja de la región, lo ubican como un país con alta consideración regional respecto a sus niveles de justicia social. No obstante ello, Uruguay se enfrenta a una situación socioeconómica caracterizada por la fragmentación social (de Martino-Bermúdez \& Morás, 2007). La situación de los/las jóvenes que no estudian ni trabajan ${ }^{1}$ es uno de los escenarios que cristalizan la desigualdad de las trayectorias juveniles que sin embargo se unifican en un futuro incierto. ${ }^{2}$

\footnotetext{
1 En el artículo utilizaremos la expresión "ni-ni” más allá de los debates que la categoría ha despertado con relación a que las personas jóvenes suelen tener ingresos intermitentes a la educación y el trabajo -principalmente informal-. Reconociendo esto, apelamos a esta expresión como forma de facilitar la comunicación.

2 Sobre las tendencias mundiales de este fenómeno remitimos a:
}

¿Cuántos son y quiénes son estos/as jóvenes que preocupan a un Uruguay acostumbrado a las mieles del reconocimiento regional e internacional?

En un reciente estudio coordinado por Rafael Rofman (2014) se encuentra que unas 102 mil personas jóvenes de Uruguay del medio urbano, de edades entre 15 y 29 años, no estudian ni trabajan, cifra que constituye el $17,1 \%$ de la población en tal franja etaria. En Montevideo, capital del país, el guarismo alcanza a 39.000 jóvenes $\left(14,4 \%\right.$ de esa población). ${ }^{3}$ Según este informe, casi ocho de cada diez de estas personas integran la población más pobre del país, viviendo en zonas marginales urbanas. Otro dato significativo es que, a pesar de la situación de desempleo, cuatro de cada diez no buscan empleo de manera activa. Si incorporamos la variable género, los datos adquieren otra

\footnotetext{
Prensa Latina y Juventud Rebelde (2015).
}

3 Si bien cuantitativamente los números absolutos pueden no impactar al lector o lectora del extranjero, cabe destacar que hablamos de una sociedad de tan solo aproximadamente tres millones de habitantes, altamente envejecida. Por otra parte, parecería que el problema no es solo nacional ni novedoso. Ver: Aparicio-Castillo (2013) y Rodríguez (2004). 
significación: aquellas que no buscan empleo, de acuerdo al texto citado, son especialmente jóvenes madres que abandonaron sus estudios. Es por ello que, si tomamos la totalidad de las jóvenes "ni-ni", el $25 \%$ de ellas se define como "ama de casa" y no busca empleo por dedicarse a tareas de cuidado. Esto demuestra que la expresión ni-ni no incluye ni reconoce el trabajo doméstico como trabajo no remunerado.

En suma, el informe de referencia da cuenta de la heterogeneidad de este grupo de jóvenes, atravesado por diversas dimensiones como las adicciones, el embarazo adolescente, la deserción educativa, las dificultades para insertarse en el mercado de trabajo, problemáticas de índole familiar y un sistema educativo que no por universalizado brinda las mismas oportunidades a todos los individuos. Tal heterogeneidad del grupo dificultaría, según el autor, el diseño de políticas y programas sociales que puedan colaborar en la inserción de estos sujetos jóvenes en la educación formal $o$ en el mercado laboral.

En tal contexto, en el presente trabajo nos preguntamos por los aspectos subjetivos y simbólicos que intervienen en las trayectorias de este sector de jóvenes; puntualmente: ¿cómo viven subjetivamente su condición estas personas jóvenes? ¿qué significados atribuyen al trabajo y a la educación? ¿... y a "no trabajar" y a "no estudiar"? ¿qué articulaciones y tensiones se dan entre el mundo afectivo y vincular de esta gente joven y el no tener trabajo ni estudiar?

Tales interrogantes responden a la dimensión simbólica de la experiencia que ha sido descuidada en los estudios sobre esta población, pero también, y principalmente, porque entendemos que es fundamental partir de la perspectiva de los jóvenes y las jóvenes para evaluar lo hecho y pensar a futuro intervenciones socio-políticas innovadoras. ${ }^{4}$

$4 \quad$ Cabe señalar que a los efectos del presente reporte de caso se han consultado los números de los últimos dos años de: (i) Revista Trabajo Social de la Editorial Eppal a nivel nacional; (ii) revista Textos e Contextos de la Universidad Católica de Rio Grande do Sul, Brasil; y (iii) Revista Plaza Pública de la Carrera Trabajo Social de la Universidad de Buenos Aires. Tal búsqueda no arrojó resultados sobre la temática desde la perspectiva que
El artículo se basa en el análisis de la práctica profesional en el Programa Jóvenes en Red, dependiente del Ministerio de Desarrollo Social, por tratarse de la única política nacional orientada a la población de interés.

De este modo, el presente texto tiene como objetivos: 1.- Identificar y analizar cuáles son las autopercepciones de los individuos jóvenes que no estudian ni trabajan, sobre su propia condición. 2.- Rastrear los valores simbólicos asociados al trabajo y al estudio. 3.- Visualizar los sentimientos que genera la situación en la autoestima e identidad de estos chicos y chicas; 4.- Analizar la densidad de sus soportes identitarios y vinculares, familiares y extrafamiliares, entendiéndolos como fortalezas que los "habilitan" en diversas dimensiones.

Este recorrido tiene además el propósito de colectivizar una propuesta de trabajo desarrollada en el marco de Jóvenes en Red. Atentos a esto, en este artículo hemos optado por brindar información sobre los aspectos metodológicos y técnico-operativos, para poner en común tanto la experiencia de trabajo como el material procesado.

\section{EI dominio empírico del trabajo profesional}

Tal como lo adelantamos, este trabajo parte de la sistematización de una práctica profesional en una de las sedes del Programa Jóvenes en Red. Según su documento de presentación ${ }^{5}$, Jóvenes en Red es un programa interinstitucional, coordinado por el Ministerio de Desarrollo Social (Mides), que conforma el sector no contributivo de la matriz de protección social reformulada bajo los gobiernos progresistas del país. Integra, junto a diversos programas, la estrategia integral de Uruguay hacia los sectores de mayores niveles de pobreza.

proponemos. Tampoco existen antecedentes estrictos en esta revista.

5 Uruguay \& Ministerio de Desarrollo Social-Mides (2012). Programa Jóvenes en RED. 
(...) está dirigido a adolescentes y jóvenes entre catorce y veinticuatro años, que no trabajan ni estudian y que no han completado el Ciclo Básico de Educación Secundaria. ${ }^{6}$ Los jóvenes deben pertenecer, además, a hogares con ingresos por debajo de la línea de pobreza. Se caracteriza por un abordaje integral, territorial y comunitario (Uruguay, Ministerio de Desarrollo Social-Mides, 2012, p. 1).

Jóvenes en Red entiende que el acceso y la permanencia en el sistema educativo y en el mercado de trabajo constituyenámbitos centrales para garantizar el cumplimiento de los derechos de la gente joven, y para la superación de la pobreza y su reproducción intergeneracional. El Programa apunta a recomponer estrategias de inclusión social a partir de un enfoque básicamente grupal. Su objetivo general es señalado como “... la promoción del ejercicio de derechos de los adolescentes y jóvenes desvinculados del sistema educativo y del mercado formal de empleo desde un abordaje integral, territorial y comunitario" (Uruguay, Ministerio de Desarrollo Social-Mides, 2012, p. 2).

El programa se ubica en sedes que se emplazan en locales de organizaciones no gubernamentales, con las cuales el Estado uruguayo ha convenido su ejecución. Tales organizaciones son de corte confesional, laico o incluso cooperativas de técnicos. Las sedes se establecen en aquellas ciudades donde la población objetivo adquiere mayor significación estadística, llegando a 36 sedes en todo el territorio nacional.

En cuanto a los recursos humanos, se asigna un/a técnico/a con perfil socio-educativo con treinta horas semanales de dedicación, cada veinte jóvenes. A eso se suma la presencia de un trabajador o trabajadora social, y un psicólogo o psicóloga. El equipo técnico así conformado -uno por sede- orienta a los sujetos adolescentes y jóvenes con el fin de disminuir los factores que

$6 \quad$ Ciclo Básico: primer tramo de educación secundaria que implica el cursado de los tres primeros años. El ciclo denominado Bachillerato completa, con otros tres años, la educación secundaria en Uruguay. provocan la distancia con el estudio y el trabajo, tratando de desarrollar diversas estrategias al respecto. Así, por ejemplo, la coordinación y derivación con instituciones educativas y la preparación para el mundo del trabajo se tornan dos ejes claros a la hora de la intervención. A modo de ejemplo, el programa organiza cursos de capacitación laboral, enseña técnicas para la elaboración de $\mathrm{CV}$, instruye sobre cómo presentarse en una entrevista de selección de personal, y analiza posibilidades concretas de trabajo. Desde el punto de vista educativo, junto a estas personas jóvenes se seleccionan cursos de capacitación orientados al trabajo, dentro del esquema de la educación pública nacional. Lo importante de esta enumeración poco atractiva, es resaltar un tipo de intervención con estricto arreglo a los objetivos literales del programa; es decir, sólo se abordan las temáticas vinculadas a trabajo y/o estudio. Esto hace que de manera menos frecuente se aborden problemáticas familiares/personales. No obstante, los equipos técnicos tienen cierta autonomía relativa para acompañar a los jóvenes y las jóvenes en sus procesos de independencia y crecimiento personal, de lo cual es ejemplo la intervención que en estas páginas se sistematiza. ${ }^{7}$

El caso que aquí hemos elegido compartir, remite al departamento de Canelones, que circunvala o envuelve de oeste a este la capital, Montevideo. Es el segundo departamento en población y densidad de población. Dentro del mismo, su segunda ciudad -Las Piedrasfue elegida para ser sistematizada a modo de caso. Si bien esta sistematización no habilita

$7 \quad$ Más allá de lo dicho, cabe destacar que el programa no atiende a todos los/las jóvenes que no estudian ni trabajan. En el último informe estadístico de Jóvenes en RED, cerrado en el primer semestre de 2014, el Programa indica que no llegó a trabajar con el $10 \%$ de la población total identificada. Muestra, además que con el 35,8\% de las personas beneficiarias no se llegó a trabajar ni en el plano educativo ni en el laboral, aspectos centrales del programa. Eso se explica por qué los jóvenes y las jóvenes presentaron carencias tales que demandaron esfuerzos técnicos "previos", tales como la regularización de la documentación (individuos indocumentados) y la atención sanitaria, ante problemas de salud importantes. Del informe de Rofman (2014) se desprende algo que, por ser obvio, no deja de ser necesario indicar: en situaciones estructurales de pobreza es sumamente difícil abordar trayectorias educacionales o laborales truncas y/o inexistentes. Tanto el Programa como el Informe Rofman señalan los límites de la propuesta. 
extrapolaciones, sí permite colocar reflexiones en torno a cierta configuración del problema, en este caso, a partir de la subjetividad de los propios sujetos adolescentes (Yin, 1989).

La experiencia desarrollada consistió en el trabajo con veintiséis adolescentes, varones y mujeres, con una prevalencia leve del sexo masculino. Las sesiones grupales a las que haremos referencia se desarrollaron aproximadamente una vez por mes a lo largo del año 2013.

\section{La estrategia metodológica y las técnicas aplicadas}

Desde un punto de vista epistemológico y en la línea del comentario anterior, el trabajo que sistematizamos es el del obrar del equipo técnico en su labor cotidiana, y se inserta en el "constructivismo social" en la medida que privilegia:

(...) el "cómo" se produce determinadas significaciones, es decir cómo se construye en un grupo determinada visión de la realidad. Ello implica necesariamente privilegiar el punto de vista interno de una comunidad o grupo, lo "emic", frente al punto de vista externo, lo "etic". El punto de partida será la visión de los sujetos, sus categorizaciones, valoraciones $\mathrm{y}$ percepciones, y la tarea del investigador, la de intérprete de lo interpretado por los sujetos (Ceirano, 2000, p. 338).

Como puede observarse, se coloca el acento en la interacción de las personas con su entorno social, tratando de evitar respuestas reduccionistas, explicaciones unidireccionales, posturas esencialistas o todo tipo de valoraciones o juicios morales que terminan por transformar algunos contingentes poblacionales en los causantes de sus propias condiciones de vida (de Martino-Bermúdez, 2013a). También se pretende evitar posturas de ajenidad sobre la situación a analizar, como si fuera provocada por distanciamientos o brechas culturales ocasionadas por la existencia, en una sociedad, de comunidades "culturales" particulares.

A partir de esta postura epistémica, se recuperan las significaciones construidas (Casas, 2006) junto a los agonistas y protagonistas. Para ello, orientamos las técnicas utilizadas a devolver la palabra a las personas jóvenes que en general no la tienen, especialmente en el ámbito educativo (Viscardi \& Alonso, 2013). Intentamos comprender qué nos dicen, con sus representaciones, sus circuitos, su estética, sus tránsitos por los espacios físicos públicos $\mathrm{y}$ domésticos.

Metodológicamente apostamos por técnicas de recolección de datos apoyadas en la producción gráfica de los jóvenes y las jóvenes. Las mismas consistieron en estimular, a partir de consignas claras, verbales y escritas, producciones gráficas que reflejan, por definición y naturaleza -como explicaremos posteriormente- sus percepciones, su personalidad y sus adquisiciones evolutivas. De las tres técnicas aplicadas, dos de ellas fueron individuales y una tercera de carácter grupal. Todas ellas estuvieron acompañadas del correspondiente y posterior debate colectivo por parte de todo el grupo, lo que fue debidamente registrado. Ordenamos a continuación las técnicas aplicadas, su objetivo, el producto concreto y la modalidad de aplicación: 


\begin{tabular}{|c|c|c|c|}
\hline Técnica & Objetivo & Producto Gráfico & $\begin{array}{l}\text { Modalidad de } \\
\text { aplicación }\end{array}$ \\
\hline El Reloj & $\begin{array}{l}\text { Analizar las actividades } \\
\text { cotidianas desarrolladas } \\
\text { por los sujetos jóvenes y } \\
\text { su distribución horaria. }\end{array}$ & $\begin{array}{l}\text { Dibujo de la esfera de un reloj en } \\
\text { papelógrafo. En cada hora "justa" el joven o } \\
\text { la joven escribe las actividades desarrolladas. }\end{array}$ & $\begin{array}{l}\text { Individual. } \\
\text { Debates en grupo } \\
\text { plenario. }\end{array}$ \\
\hline $\begin{array}{l}\text { Mapa de } \\
\text { Red }\end{array}$ & $\begin{array}{l}\text { Analizar la trama vincular } \\
\text { de los individuos jóvenes } \\
\text { en cuatro esferas: laboral, } \\
\text { educativa, familiar, } \\
\text { comunitaria. }\end{array}$ & $\begin{array}{l}\text { Una hoja dividida en cuadrantes de acuerdo } \\
\text { a cada esfera señalada. En cada cuadrante se } \\
\text { dibujan los signos de "hombre" o "mujer" } \\
\text { por cada persona referente con la que se } \\
\text { mantiene un vínculo estable, y se anota el } \\
\text { tipo de vínculo (madre, maestro, educador, } \\
\text { amiga). Respecto a la calidad del vínculo, } \\
\text { si éste era positivo se identificaba además } \\
\text { con el signo +, si era negativo por el de-. La } \\
\text { distancia respecto al centro de cada vínculo } \\
\text { graficado indicaba la intensidad del vínculo. }\end{array}$ & $\begin{array}{l}\text { Individual. } \\
\text { Debates en grupos } \\
\text { plenario }\end{array}$ \\
\hline Identikit & $\begin{array}{l}\text { Analizar las } \\
\text { autopercepciones de } \\
\text { los individuos jóvenes } \\
\text { respecto a su propia } \\
\text { condición así como las } \\
\text { valoraciones imputadas al } \\
\text { trabajo y estudio. }\end{array}$ & $\begin{array}{l}\text { Tres dibujos (identikits) elaborados cada } \\
\text { uno de ellos por un subgrupo de jóvenes. } \\
\text { Tales dibujos remitían a: } 1 \text {. -sujeto joven } \\
\text { trabajador; } 2 \text {. -joven estudiante; } 3 \text {. -joven que } \\
\text { no estudia ni trabaja. }\end{array}$ & $\begin{array}{l}\text { Grupal } \\
\text { (Grupo general dividido } \\
\text { en tres sub-grupos) } \\
\text { Debates en grupo } \\
\text { plenario. }\end{array}$ \\
\hline
\end{tabular}

Pero ¿qué subyace a esta tabla y a estas técnicas? Está en juego el significado psicoanalítico de las técnicas proyectivas y del espacio grupal como espacio de objetivación. Es desde esta perspectiva que proponemos las técnicas y analizamos sus productos. ${ }^{8}$

Tales técnicas están asociadas al concepto freudiano de proyección. En un primermomento, Freud define la proyección como mecanismo de defensa subyacente a problemáticas paranoides. Es decir, el concepto de proyección estuvo asociado a la clínica de patologías psicológicas (Freud, 1984, 1991). Posteriormente, el propio Freud amplía este concepto, independizándolo de su carácter patológico y abordándolo como un "colocar" afuera elementos inconscientes asociados a las diversas conductas del sujeto, incluso en situaciones de "normalidad" (Freud,

$8 \quad$ Cabe aclarar que la interpretación de los identikit y materiales en general la realizamos básicamente a partir de la obra de Freud (1973, 1979, 1984, 1999) y Winnicott (1971, 1981a, 1981b), autores de referencia en este tipo de análisis que ha constituido la base del desempeño clínico del Lic. F. López.
1973). En sintonía con ello, puede entenderse este conjunto de técnicas, de manera muy amplia, como herramientas sensibles a aspectos inconscientes de toda conducta humana9 .

A la hora de aplicar las técnicas descriptas, hemos analizado también los aspectos lúdicos a ellas asociados. Estos instrumentos permiten analizar aspectos dolorosos a través de una mediación necesaria, como pueden ser los productos gráficos. Obviamente reconocemos que deben salvarse las distancias con las elaboraciones de Freud (1991) y Winnicott (1981b) respecto al juego en ámbitos clínicos. Es decir, no se entienden estas técnicas como objetos transicionales, sino que en cierta manera se basan en un "juego" - dibujar-que permite un manejo más "leve" de lo doloroso. Las técnicas puestas a disposición desempeñarían el papel de significantes a partir de los cuáles

9 Para un abordaje interesante y pedagógico recomendamos la lectura de Vives (2005). Para un abordaje desde la perspectiva cognitiva sugerimos Anderson y Anderson (1963), y Lindsay y Norman (1983). 
el o la joven, en este caso, alude a significados asociados a la problemática en cuestión (Freud, 1973, 1984, 1991; Winnicott, 1981a, 1981b).

A esta forma de comprender las técnicas proyectivas sumamos la consideración del espacio grupal como una suerte de zona mediadora entre una realidad personal dolorosa y la capacidad de simbolización sobre la misma, como zona mediadora entre lo individual y lo colectivo, lo material y lo simbólico. Es Winnicott (1981b) el autor que permite reunir estos aspectos. Para el autor, el juego es siempre actividad creativa, liberadora y esencialmente simbólica, pero es también un espacio diferente al mundo exterior y al mundo interior. El autor define una línea de acumulación o crecimiento: “... hay un desarrollo que va de los fenómenos transicionales al juego, de éste al juego compartido y de él a las experiencias culturales" (p. 76). En este sentido, intentamos conciliar el "juego" individual, con los espacios grupales de reflexión, tratando de alimentar en la gente joven otras formas de posicionarse ante su situación.

Porúltimo, cabedestacarquelaconfiabilidad de este tipo de técnicas ha sido cuestionada. Son acusadas de poseer una débil cientificidad, en la medida que: 1.- no buscan una norma o una ley universal sino la tónica individual, lo singular, por tanto estarían atadas a lo azaroso de las experiencias particulares; y 2.- la persona puede manejar conscientemente las respuestas. Pero lo que se destaca es su ductilidad para abordar cómo el individuo se siente y se piensa en contextos exploratorios, tanto a nivel de investigación como de intervención. Es por ello que, atendiendo los objetivos, las consideramos sumamente apropiadas en ambos sentidos teniendo en cuenta las escasas elaboraciones en torno al tema. ${ }^{10}$

\section{Breves consideraciones teóricas}

En primer lugar, nos interesa destacar lo que llamamos el carácter residual de la categoría "ni- ni" respecto de la juventud. Como ya sabemos, el abordaje de la juventud

10 Sobre la versatilidad de las técnicas de investigación a los efectos de la intervención y viceversa, se recomienda la lectura de Mitjavila (1998). que no estudia ni trabaja ha sido generalmente sintetizado por el acrónimo "ni-ni". Ya los prefijos en negativo indican falencia, ausencia y una pronunciada ambigüedad. Denominados de tal manera, parecería que el sujeto joven $n i$-ni es un o una "joven problema" y sustantivamente su naturaleza es posiblemente "desviada".

Resulta interesante y gráfica para el cometido de este apartado la revisión histórica sobre juventud que hacen Feixa, Molina y Alsinet (2002), quienes proponen cinco grandes modelos de juventud que funcionan como tipos ideales: a) el púber para la sociedad primitiva (sociedades segmentadas sin Estado); b) el efebo para la sociedad antigua; c) los mozos para el Antiguo Régimen (sociedades campesinas preindustriales); d) los muchachos y muchachas en la sociedad industrial; e) la sociedad posindustrial, caracterizada por la irrupción de la juventud como sector protagonista en la escena pública.

Superadas las figuras de los "muchachos y muchachas" vinculados al mundo del trabajo y sus "peligros", la juventud aparece como "agente" colectivo. Reguillo (2012) indica:

Los jóvenes han adquirido visibilidad social como actores diferenciados a través de su paso, por afirmación o negatividad, por las instituciones de socialización, por el conjunto de políticas y normas jurídicas que definen su estatuto ciudadano para protegerlo y castigarlo, o por la frecuentación, consumo y acceso a un cierto tipo de bienes simbólicos y productos culturales específicos (p. 51).

Los mecanismos de construcción del otro como diferente, como sucedía en el operativo básico de la dominación colonial donde el otro -entre ellos el sujeto joven- era profundamente "desigual", alguien que "vale menos" por ser diferente, hoy actuarían de manera contraria (Araújo, Del Signore, Freíd, Morás, Muñoz \& Larreta, 1991). Si en las colonias de las sociedades pre-capitalistas y en los barrios populares de la sociedad industrial había delincuentes, vagos pero no "jóvenes" ni movimientos juveniles, las últimas décadas del siglo XX y el nuevo siglo trajeron aparejada a la juventud como protagonista y agonista 
destacada. Frente a una apresurada oclusión de la figura del individuo "trabajador" o "proletario", los sujetos jóvenes ocupan un lugar de relieve en la topografía sociopolítica de la sociedad posindustrial (Perrot, 1996).

Lo que queremos señalar es que ante la problemática que se estudia, parecería que la "juventud" aparece como lo universal contra lo que se opone, como negativo fotográfico, la "juventud ni-ni". Si "vago" u "obrero" eran los actores dicotómicos principales en las sociedades industriales y no existía espacio social ni de enunciación para la juventud, ahora es la "juventud" el campo donde se enuncia a este grupo de jóvenes como residuo, como conjunto de carencias.

Las formas de enunciar se transforman en cuadros donde se delimitan claramente lo que se debe tomar como figura y lo que se debe colocar como fondo. Muy al fondo, definir algo o a alguien por la negativa es, entre otras cosas, subordinar su existencia a algo que desde el inicio es considerado superior y de mayor valor (Auyero, 1993). Definir o construir un colectivo desde una negatividad radical genera variados perjuicios en su seno. Así, por ejemplo, se podría hablar de una especie de formateo de las subjetividades de los individuos, quienes terminarían por actuar los guiones preconstruidos, en el fenómeno analizado por Merton (2003) como profecía autocumplida. ${ }^{11}$ Pero, paradójicamente, las instituciones que enuncian de esta manera el problema son instituciones "desfondadas", "estrelladas", como la escuela o los centros educativos, sustantivos para este tema. Instituciones que ya no generan ni infancia ni adolescencia (Duschatzky \& Corea, 2002; Fernández, 1999).

Estamos frente a verdaderos procesos de "desintitucionalización" de aquellas entidades constructoras de infancias y juventudes como lo son las instituciones educativas (Dubet, 2006, 2013; Duschatzky \& Corea, 2002; Fernández, 1999). Existe un distanciamiento profundo entre sus marcos institucionales y las personas jóvenes: se tornan menos habitables para ellos y van perdiendo, ante sus ojos, su profunda

11 Sobre una crítica a la expresión "ni-ni" remitimos a: Negrete y Leyva (2013) y Feijó y Botinelli (2014). significación (Condon, González, Prego \& Scarone, 2012; Chaves, 2010).

El sistema educativo en general $y$ la enseñanza media en particular se han tornado para muchos/as jóvenes, en espacios sumamente frustrantes de acuerdo a la literatura citada: programas poco atractivos; falta de diálogo entre docentes y estudiantes, etc. Esta frustración parece explicar una parte importante del malestar docente, que percibe la falta de sentido de los hechos, utilizando un lenguaje que sugiere la simulación de una experiencia vivida y no una verdadera comunicación (Viscardi \& Alonso, 2013).

En este mundo invadido por imágenes y estereotipos en torno a un modo hegemónico de juventud o adolescencia, los sujetos jóvenes pobres, entre ellos los ni-ni y especialmente los varones pobres, son ubicados del lado de la irracionalidad, de la violencia. Los más excluidos son los más estigmatizados, son los que provienen de los infiernos urbanos. El uso y abuso de estas discursividades, en primer lugar, participa en la creación de un clima o atmósfera social donde el joven varón pobre se torna en enemigo público, erosionando seriamente sus posibilidades de integración en los espacios educativos y laborales.

La mujer joven pobre, por otra parte, comienza a asociarse fuertemente a la figura del ama de casa y madre cuidadora pasible de sospechas y sanciones (Viscardi \& Alonso, 2013); además, naturaliza una situación de supuesta inacción, cuando el no trabajar ni estudiar es, muchas veces, algo intermitente, constituye "cortes" cuando, obviamente y desde una perspectiva de género, el trabajo doméstico no remunerado es trabajo al fin.

El género no resulta una dimensión explicativa de la situación "ni-ni” pero sí nos permite interpretar de manera muy clara las diferencias existentes en los circuitos recorridos por estas personas jóvenes. Por lo tanto, incorporar la variable de género nos aleja de las teorías estrictamente performáticas del género que en su postura más radical abordan al mismo como mera etiqueta y con un casi nulo valor heurístico (de Martino-Bermúdez, 2013b) ${ }^{12}$.

12 Básicamente nos referimos con esta crítica a la obra de Judith Butler (1990). 
Es decir, sostenemos que ciertas posturas posmodernas que describen las narrativas de género totalizadoras crean una falsa homogeneidad en colectivos -mujeres $\mathrm{u}$ hombres- que son básicamente heterogéneos. Además, han puesto en duda la oposición binaria que fija a hombres y mujeres en sus cuerpos, desafiando así la base de la distinción sexo/ género. Estas posturas pueden bien sintetizarse en la siguiente cita:

Si hay algo en común entre diversos autores que parten de las diferencias entre los sexos, es la importancia otorgada a las relaciones de poder, a las instituciones, prácticas y discursos que establecen y regulan la forma y significado del género. En otras palabras, a los dispositivos que permiten que los sexos sean establecidos. Dispositivos y prácticas entre las cuáles se puede enumerar: el falocentrismo, la norma que establece como padrón normativo la heterosexualidad, el tabú del incesto. Todas estas concepciones internalizadas, naturalizan la agencia sexual masculina, la colocan como padrón que marca la diferencia y la opresión (Beauvoir, 2000) y el constreñimiento de las prácticas del agente en un orden social dado (Connell, 1987).

Tales prácticas funcionan en un complejo circuito de prohibición, producción $\mathrm{y}$ naturalización del sexo/género/deseo, y es en ese circuito donde se insertan las prácticas de estas personas jóvenes, más o menos públicas, más o menos visibilizadas. A modo de ejemplo, las diferencias entre los espacios donde ellas circulan, las diferencias entre las actividades a las que destinan su tiempo libre son abordadas, en este trabajo, como prácticas de producción -tanto cultural como materialde los géneros. Esto es así en la medida en que las mismas trasladan acríticamente significados e imposiciones atribuidas socialmente a cada sexo (Beauvoir, 2000; Irigaray, 1985; de Martino-Bermúdez, 2013b).

\section{Análisis del material recogido por cada técnica aplicada}

\subsection{La técnica del Reloj}

La técnica El Reloj ${ }^{13}$ permite las siguientes observaciones. Son los varones quienes irrumpen en el espacio público, pero un espacio público reducido geográficamente. Ellos están en las esquinas, las calles, las plazas, en los alrededores de los centros educativos. Dicen:

"Voy a la esquina." "Pasamos por el Liceo Nro. 2." "A veces voy a la plaza."

"Voy a la casa de mis amigos."

Llama la atención que las puertas de los centros educativos sean el espacio elegido para socializar por parte de aquellos sujetos para quienes ha dejado de ser atractiva la educación formal; resulta una metáfora sobre la cual la sociedad uruguaya debe pensar. Los individuos jóvenes "ni-ni", al elegir ese ámbito fronterizo, enuncian y denuncian mucho más de lo hasta ahora soportado por los umbrales de tolerancia de la sociedad uruguaya. La puerta no es atravesada, tampoco está en la calle o vereda: estar a la puerta, pero afuera, implica el reconocimiento del centro escolar pero la imposibilidad de ingresar y mantenerse en él. Tal vez estén simulando ser parte de una institución a la que se sienten impulsados pero que no logra atraerlos y que no logran habitar. Las personas jóvenes ni-ni eligen esa frontera, entre calle y escuela.

La juventud ha sido definida como un proceso de emancipación respecto de la familia de origen y de articulación de una identidad propia, expresada por antonomasia en el mundo público y laboral. Pero las jóvenes ni$n i$ se encuentran claramente atadas al ámbito doméstico, resignificando así el hogar de origen. Nos dicen y se dicen:

"Ayudo en las tareas de la casa." "Cocino." "Miro tele." "Tomo mate."

"Me acuesto a dormir." "Limpio la casa."

Sus palabras marcan una clara lógica de poder, de dominación, donde el orden social dominante y masculino está tan profundamente

13 Los jóvenes debían dibujar en reloj y en cada hora "justa" indicar las actividades que realizaban. Nos remitimos al cuadro elaborado. 
arraigado que no requiere justificación, se impone a sí mismo como autoevidente y es tomado como "natural". Orden que se logra gracias al acuerdo casi perfecto e inmediato que obtiene de las estructuras sociales como la organización social del espacio y tiempo y la división sexual del trabajo, y por otro lado, de estructuras cognitivas inscriptas en los cuerpos y en las mentes; campo y habitus que refuerzan el sistema patriarcal y adultocéntrico.

En palabras de Bourdieu (2000), "la historia hecha institución" y "la historia hecha carne". Los estereotipos imputados a cada sexo cristalizan de manera muy radical en las identidades de estas jóvenes. Sus circuitos en el ámbito público duran poco tiempo, la actividad doméstica estrictamente asociada a la reproducción se encuentra naturalizada y este orden simbólico se cronifica una vez que se transforman en madres. Parecería que son espectadoras de su propia existencia o espectadoras de vidas ajenas "estetizadas":

"Miro TV." "Escucho radio." "Miro informativo." "Miro comedias.".

Colocan a sus hijos e hijas en la condición de "ortopedia afectiva" con las que tratan de superar sus múltiples ausencias y frustraciones. En torno a la relación con sus hijos e hijas, se conforman verdaderos mecanismos compensatorios en los cuales se funden carencias afectivas y materiales que la joven madre ha padecido y padece.

"Llevo a mi hijo a la guardería." "Llevo a mi hermana a la escuela."

"Acompaño a mi madre al médico." "Voy a buscar a mi hija al jardín."

Para estas jóvenes, la juventud ha consistido habitualmente en el tránsito de una dependencia familiar a otra, ubicadas ambas en la esfera privada. La reclusión femenina en el espacio doméstico las ha alejado de la calle o de los locales de ocio, espacios privilegiados para los jóvenes varones. Su espacio es el estrictamente doméstico, asociado a la reproducción y al cuidado intergeneracional y pautado -diríamospor la vivencia de un tiempo lineal, asociada al transcurso natural del mismo. El desarrollo del día secuencia las actividades a desarrollar. El tiempo de los jóvenes es también lineal, asociado a un espacio público muy acotado.

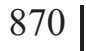

Por ello, más allá de las diferencias entre los géneros, podríamos indicar una tendencia hacia la domesticidad muy marcada en los individuos jóvenes "ni-ni" de ambos sexos, extendiendo lo doméstico a lo barrial "conocido", "cotidiano". Esta "domesticidad" se desarrolla dentro de un estilo de vida que en otras oportunidades hemos de llamar "óntico", es decir, donde la capacidad de tomar decisiones vitales sobre la propia vida se encuentra muy reducida (de MartinoBermúdez, 2000).

\subsection{Los Mapas de Red}

Vale recordar aquí que cada joven debía diagramar sus vínculos, la calidad de los mismos y las personas con las que los mantienen. Al iniciar las sesiones de trabajo grupal surgieron los siguientes comentarios:

"Yo no tengo a nadie." "Me llevo mal con todo el mundo."

"Nadie estudia ni trabaja, estamos en el horno."

"Mis amigos son todos varones." "Solo tengo a mi familia."

"Varones y mujeres no pueden ser amigos."

"Dejé el liceo y no vi más a mis amigos." "En esa UTU ${ }^{14}$ todos te miraban mal."

El hacer visible estas situaciones hace posible trabajarlas. Cuando un joven logra decirse a sí mismo esas cosas, son gritos que duelen, que lastiman pero que nos interrogan y los interroga, nos y los interpela. Es decir, colocan la institución y la política como parte del problema.

Se detecta una importante pobreza en la trama vincular de estos sujetos jóvenes, donde los lazos con ámbitos laborales o educativos no existen. Si los lazos y espacios de socialización con aquellos que aun estudian o trabajan se cortan, la realidad interpersonal que se configura carece de fortaleza para habilitar o impulsar procesos de inserción a nivel laboral o educativo. Los modelos de identificación y de imitación son o pueden ser considerados de muy baja intensidad, es decir, no reúnen elementos para impulsar procesos de movilidad

14 Refiere a un local de estudio perteneciente al nivel secundario técnico denominado Universidad del Trabajo del Uruguay (UTU). 
y cambio social. Se generan perspectivas y representaciones de movilidad descendente (Katzman, 2001).

La escasa densidad de sus redes vinculares -el adolescente que identificó más vínculos representó siete personas- nos muestra que nos encontramos con jóvenes bastante solos, en situaciones de angustia y aislamiento, contando básicamente con sus familias como sistema de referencia. La concentración de los vínculos en la familia incide en las posibilidades reales de emancipación, ya que el aglutinamiento familiar dificulta seriamente las posibilidades de que los miembros jóvenes se proyecten fuera de la misma.

Este aspecto vincular refuerza la "domesticidad" también en términos psicosociales. Los vínculos presentan una homogeneidad importante. Son vínculos con sus pares, en la misma situación "ni-ni". No se observan vínculos con el mundo adulto más allá de sus familias. Las representaciones sobre el mundo adulto son limitadas, asociadas a las "fugas" del sistema familiar, lo que dificulta la adaptación a otros escenarios como lo es el mundo del trabajo.

La homogeneidad también se expresa en vínculos limitados al barrio que proclaman la segregación residencial que caracteriza al Uruguay de hoy, generando procesos de integración social marginal.

Otro aspecto a destacar es que los discursos de estos sujetos jóvenes se caracterizan por lo que Kaplún (2008) ha denominado "resacas sexistas". La relación entre los sexos se encuadra en el entorno familiar fuera del cual el vínculo queda supeditado a la actividad sexual y la reproducción. Dentro de las "resacas sexistas" encontramos frases como: "la esquina es de los varones", "si la piba para en la esquina con nosotros... es porque quiere algo", haciendo alusión a un supuesto interés sexual. En resumen, los prestadores de identidad, para estos chicos y chicas, son escasos y endogámicos, tendiendo a una homogeneización y domesticidad psicosocial.

\subsection{Los identikit}

Ordenamos el material y su análisis de acuerdo a cada uno de los "identikit" consignados: el dibujo del o la joven trabajadora, el del joven o la joven estudiante y, por último, el del o la joven "ni-ni".

El sujeto joven que estudia. El dibujo presenta un joven en el marco de una institución educativa, donde son claras las líneas de apoyo que lo sostienen. La institución le da la posibilidad de despegarse del suelo a partir de una serie de escalones que dan cuenta de una trayectoria ascendente. Existe una configuración espacial donde podemos destacar figura y fondo, las cuales están en relación de continente y contenido. También se visualiza un sol que asoma entre las nubes, lo que nos da la idea de una claridad que emerge con fuerza. Aparecen otros seres vivos que rodean al sujeto, un ambiente no degradado que nos hace pensar en la incidencia de elementos que nutren y relacionan al sujeto y su situación con la vida. Su vestimenta se asemeja a un uniforme que lo identifica y lo diferencia. Las palabras que acompañan al dibujo refuerzan su identidad y su rol social de estudiante. Por ejemplo: " $a$ mí me gusta estudiar para ser alguien en la vida", "estoy yendo al liceo a estudiar y me gusta la matemática”. Es un sujeto identificado y "pre-formateado" por los mandatos sociales y culturales -el estudio visualizado e investido como palanca de movilidad social ascendente-. El sol y su fuerza significarían aquello que para ser alguien y tener frutos hay que estudiar. El estudio transforma, así, al viviente en sujeto, otorgándole identidad social, es decir, siendo reconocido y significante para sí y para los otros.

Por último, cabe destacar que otros símbolos acompañan al identikit: una bandera nacional que refiere a la conformación de una ciudadanía inclusiva, a la identificación y al ser parte de un universo simbólico que integra y trasciende las particularidades de lo local.

Es el universo simbólico tradicionalmente asociado a la educación: permite la movilidad social ascendente y califica(ba) en el Uruguay meritocrático y de cercanías que ya no es (Real de Azúa, 1990).

El sujeto joven trabajador. El sujeto joven no está enmarcado en una institución sino en la calle, donde desempeña una actividad laboral que consiste en entregar alimentos a domicilio, 
trabajo que no requiere alta calificación $\mathrm{y}$, muchas veces, está caracterizado por la informalidad. El dibujo representa a un joven de aspecto "prolijo", de pelo corto, sin tatuajes ni pircing. Presenta un gesto de satisfacción (risa) y su vestimenta se asemeja a la de un uniforme de trabajo en el cual se señala un negocio fácilmente identificable en el barrio de la sede. Esta referencia espacial se ve reforzada por la "dirección" -domicilio- donde se entrega la compra que aparece en el dibujo.

Caben dos acotaciones: en primer lugar, la presencia sistemática del rubro alimentación, asociada a la función nutricia, ya sea en los dibujos analizados como en los temas de capacitación solicitados por estos individuos jóvenes. Esta apelación al alimento funcionaría como una especie de ecuación cognitiva para dar respuesta a dos grandes necesidades: alimentación y trabajo. Lo paradójico es que la oferta educativa a las que apunta el Programa reproduce esta lógica sin considerar las necesidades del mercado de empleo y sin explorar con los jóvenes y las jóvenes otras opciones. En segundo lugar, debemos destacar que es muy difícil para esta gente joven visualizarse fuera del lugar de residencia. Prefieren no salir del barrio aun perdiendo así oportunidades laborales. Se encuentran segregados territorialmente, en ciudades fuertemente segmentadas, pero también reproducen simbólicamente tales fronteras.

Completa el dibujo un carrito que cumple la función de organizar la tarea y que representaría una vía de comunicación para el afuera. Es decir, permite llevar a un "otro" algo que pide y necesita, pero ese afuera siempre se encuentra en los límites del barrio ya conocido, en los límites de lo cotidiano y de lo doméstico. Las palabras del personaje dan cuenta de un diálogo intergeneracional ("Sírvase, señora. Gracias por su compra"), así como también el manejo de códigos convencionales de comunicación, códigos sociales y culturalmente asociados a la buena educación. El trabajo aparece representado como herramienta de inclusión social que a su vez habilita el diálogo con el otro sujeto adulto.

En cuanto al fondo que lo rodea, es similar al que planteamos para el caso anterior: presencia de seres vivos, ambiente no degradado, sol/ símbolo. El desdibujamiento de los parámetros institucionales en el mundo del trabajo -trabajo en la calle, posiblemente poco calificado, precario, sin prestaciones sociales- estaría reflejando las posibilidades laborales que estas personas jóvenes visualizan para sí, sea o no en el marco del Programa. Más allá del valor otorgado al trabajo, parecería que los jóvenes y las jóvenes son conscientes de las dificultades para el ingreso al mercado laboral y expresan un bajo umbral de aspiraciones.

El sujeto joven ni-ni. El dibujo nos presenta a un joven con el pelo enmarañado, con un gesto indefinido -sonrisa que no llega a serlo-. El cuerpo tiene diversos pircing $y$ tatuajes, elementos que generan lazos en el endogrupo pero dificultan anclajes sociales más generales o claramente determinados por lo instituido. Se conocen las quejas que emergen de las instituciones ya sean educativas o laborales, respecto a estos elementos que son rápidamente transformados en señales de "problemas", "desvíos", etc.

El escenario es la calle/esquina, como espacio vinculante con el entramado social. Se remarcan identificaciones con las barras de fútbol, las cuales transitan y marcan los espacios urbanos como si se tratara de una especie de ritual de apropiación simbólica por parte de una tribu urbana ("Esquina Manya"15). También se le asignan al joven elementos que hacen referencia al consumo de sustancias (cigarrillo, alcohol). "Vamos a tomar un vino", es el diálogo que mantiene con un igual. El dibujo está cargado de estigmatizaciones sociales, las cuales son homogeneizantes y evidentemente no capturan la diversidad de identidades juveniles.

El escenario está casi vacío de contenidos, descontextualizado: no existen elementos que den cuenta del momento del día, no se dibuja el suelo por debajo del joven ni el cielo por encima. Paradójicamente es un escenario ni-ni: ni suelo, ni cielo, ni tiempo, ni espacio. Es un joven sin soportes, sin elementos que lo enmarquen o contengan, ubicado en coordenadas tempoespaciales desdibujadas, una especie de "limbo

15 Manya: refiere a la preferencia por uno de los equipos de fútbol tradicionales y más antiguos en Uruguay. 
social". Es una esquina, en cualquier lugar, en cualquier momento, en un barrio popular de Buenos Aires, Montevideo o Santiago. Lo que permitiría identificar la nación es la inscripción "Manya" y no el sol reluciente. No hay instituciones, bandera ni barrio.

Los elementos vitales-nutricios que rodean al joven son casi imperceptibles, como si el joven transitara por circuitos de baja intensidad social y por ende de baja intensidad de vida. En el caso del sujeto joven estudiante, el diálogo es consigo mismo -sujeto autorreflexivo-. En el caso del sujeto joven trabajador es un dialogo intergeneracional. En el caso del sujeto joven $n i-n i$ es un dialogo con otro igual a él, que maneja los mismos códigos, es decir, una relación homogénea donde se refuerzan las similitudes de exclusión y autoexclusión.

El sol/símbolo no existe. Tal vez por aquello de ya no esperar que el futuro depare acontecimientos diferentes al hoy. El tiempo transcurre y la cotidianeidad no es investida de acontecimientos relevantes y significativos.

La cruz -la religiosidad- aparece como un elemento presente en la vida de estos individuos jóvenes. Acotamos que en el desempeño profesional se ha detectado que muchas veces se acercan a las comunidades religiosas buscando ayuda para superar el consumo problemático de sustancias psico-activas.

\section{Reflexiones finales}

Es muy claro ubicar a los y las jóvenes $n i-n i$ y su visibilidad social en la primera consideración mencionada siguiendo a Reguillo (2012), es decir, por la negatividad existente en su trayectoria a través de las instituciones de socialización. Tal es así que su propia denominación (ni-ni) en los medios, en las políticas y programas y en los diversos discursos sociales, se configuran como un a priori monstruoso que invisibiliza otras dimensiones y heterogeneidades configuradas en sus trayectorias vitales.

Se señala particularmente el proceso de homogeneización a partir del cual se van instaurando representaciones absolutas y esencialistas sobre los jóvenes ni-ni que funcionan a modo de axiomas irrefutables, verdades absolutas que no admiten discusión, pero que lejos de explicar algo, inhiben todo análisis profundo y alternativo, como si se tratara de "una estrategia para hacer invisibles los problemas sociales" (Wacquant, 2006, p. 61).

Pero detrás del estereotipo del joven "ni-ni", como representación absoluta, encontramos no solo que los propios adolescentes lo reproducen, sino que nos dicen: No tengo a nadie; Escucho la radio; Cuido a mis hermanos. Si bien aspiran a ser estudiantes o trabajadores, se autoperciben como jóvenes sin futuro, aislados, con escasas posibilidades de comunicación con otros. Un conjunto de vivencias que no deben ser invisibilizadas por un estereotipo que no llega a dar cuenta de la complejidad de la temática, y se limita a individualizar los problemas sociales, responsabilizando a la persona joven y a su familia.

Denominar desde una negatividad radical estos problemas sociales, enunciados y sentidos por estos individuos jóvenes, es también construir desde una negatividad radical una forma de ser y sentir imputada a ellos. La imposición de una construcción social nociva termina delineando una lógica social donde lo importante no es lo que efectivamente pasa, sino lo que la gente cree que pasa. Cuando se definen determinadas situaciones como reales, éstas comienzan a ser reales en sus consecuencias, aunque la definición no se corresponda con la realidad (Giorgi, Kaplún \& Morás, 2012).

No podemos dejar de lado los discursos institucionales que no deben ser abordados como el punto de encuentro de realidad y lenguaje (Foucault, 2002), sino como verdaderos discursos normativos que "seleccionan" algunas dimensiones del problema transformándolas justamente en sustantivas y permanentes, como atributos de los grupos sociales que viven esa problemática (D’Alessandra, 2013), de manera tal que convierten un problema sumamente complejo en casi un atributo de los sujetos jóvenes especialmente pobres. Es decir, el Programa no sólo elaboraría interpretaciones del problema sino atributos personales de la gente joven que lo vive (de Martino-Bermúdez, 2012, 2014). Además, como toda institución, generaría espacios de efectividad de tales enunciados de 
"verdad" (Balibar, 1995). Pensar la situación como atributos personales es el extremo de la individualización y la responsabilización de los y las jóvenes.

La institución -junto con otros agentes sociales- pasa a ser una cantera de verdaderas invenciones ideológicas sobre la realidad, que son desplegadas en el entramado social, bajo el rótulo de difusión neutral y objetiva. Imágenes sociales fuertemente estigmatizantes sobre los sujetos jóvenes $n i$-ni -jóvenes pobres en general-, nutren el universo simbólico de los propios agonistas. Éstos terminarían conformando su identidad con base en supuestos comportamientos juveniles que, sin ser de su exclusividad, son asociados sólo a ellos: consumo de sustancias adictivas, dificultades en el aprendizaje, etc.

Lo que nos interesa remarcar es que las autopercepciones de los jóvenes y las jóvenes se basan en rasgos que toman de identidades proscriptas, repitiendo los estigmas de las representaciones sociales dominantes sobre ellos. Dentro del propio grupo de $n i-n i$ queda invisibilizado el carácter discriminador de tales representaciones: el individuo joven como ser inseguro, como ser no productivo, como ser incompleto, como ser desinteresado y asexuado, como desviado, como peligroso.

A esta homogeneización se suma el proceso de domesticidad vivido por estas personas jóvenes, en la medida en que los espacios a los que acceden se asocian fuertemente a lo conocido: familia y barrio. El estar "cercado", sin posibilidades de movilidad social, es prácticamente una experiencia vital que se torna naturalizada y reproducida espacial -espacio privado- y geográficamente -barrio-.

Pensar los centros educativos y el mundo del trabajo como espacios de construcción de ciudadanía y participación, al alcance y habitables para la gente joven, es un desafío de primer orden que debe colocarse en toda agenda política para superar el registro meramente individual de estas complejas problemáticas sociales (Agudelo-Ramírez, Murillo-Saá, Echeverry-Restrepo \& Patiño-López, 2013). Así también, analizar las instituciones como "productoras" y "legitimadoras" de saberes y verdades, es otro desafío para la comprensión de los diversos factores que participan en la intervención socio-política y tecno-operativa. Ampliar los espacios de constitución de una identidad juvenil no estigmatizada es otro pendiente.

Todo ello se torna difícil si las autopercepciones juveniles se basan y se fomentan a partir de rasgos ideo-políticos de un Uruguay que ya no es. Es decir, un Uruguay donde ya no existe una movilidad social ascendente garantizada por la educación, profundamente meritocrático y cercano (Real de Azúa, 1990).

En nuestro país -y no sólo en él- se tornan relevantes estos desafíos, especialmente porque existen muy escasas producciones técnicas sobre estas líneas problemas y sus dimensiones técnico-operativas, tanto en términos materiales como simbólicos.

En este artículo intentamos colocar a disposición una línea de intervención desarrollada en un programa específico y sus hallazgos primarios. Pero especialmente buscamos compartir con los lectores y lectoras las significaciones de estos sujetos jóvenes uruguayos. Esperamos haberlo logrado.

\section{Lista de referencias}

Agudelo-Ramírez, A.; Murillo-Saá, L.; Echeverry-Restrepo, L. \& PatiñoLópez, J. A. (2013). Participación ciudadana y prácticas políticas de jóvenes en la cotidianidad. Revista Latinoamericana de Ciencias Sociales, Niñez y Juventud, 11 (2), pp. 587-602. Doi: 10.11600/1692715x.1129250612.

Anderson, H. \& Anderson, J. (1963). Técnicas proyectivas del diagnóstico psicológico. Madrid: Rialp.

Aparicio-Castillo,P.(2013). Educar y trabajar en contextos de precariedad y desigualdad en América Latina. Jóvenes en debate. Revista Latinoamericana de Ciencias Sociales, Niñez y Juventud, 11 (2), pp. 527-546. Doi: 10.11600/1692715x.1125121012.

Araújo, A.; Del Signore, G.; Freíd, G.; Morás, L.; Muñoz, B. \& Larreta, A. (1991). Jóvenes: una sensibilidad buscada. Montevideo: Nordan. 
Auyero, J. (1993). Otra vez en la vía. Notas e interrogantes sobre la juventud de sectores populares. Buenos Aires: Fundación del Sur, Espacio Editorial.

Balibar, E. (1995). Nombres y lugares de la verdad. Buenos Aires: Nueva Visión.

Bourdieu, P. (2000). Poder, derecho y clases sociales. Las formas del capital. Bilbao: Desclée.

Butler, J. (1990). Gender Trouble: Feminism and the Subversion of Identitiy. Nueva York: Routledge.

Casas, F. (2006). Infancia y representaciones sociales. Política y Sociedad, 43 (1), pp. 27-42.

Ceirano, V. (2000). Las representaciones sociales de la pobreza. Cinta de Moebio, (9), pp. 337-350. Recuperado de: http:// www.moebio.uchile.cl/09/ceirano.htm

Condon, F.; González, D.; Prego, C. \& Scarone, B. (2012). Los derechos de las niñas, niños $y$ adolescentes privados del cuidado de su familia total o parcialmente. Análisis de su estado de cumplimiento. Montevideo: Aldeas Infantiles SOS.

Connell, R. (1987). Gender and Power. California: Stanford University Press.

Chaves, M. (2010). Jóvenes, Territorios y Complicidades. Una Antropología de la Juventud Urbana. Buenos Aires: Espacio.

D’Alessandra, V. (2013). Soy lo que ves y no es. Adolescentes y jóvenes que no estudian ni trabajan en América Latina. Buenos Aires: Unesco.

De Beauvoir, S. (2000). O Segundo Sexo. Rio de Janeiro: Nova Fronteira.

De Martino-Bermúdez, M. (2000). Familias, Género e Integración Regional. Un ejemplo en el Mercosur: la ciudad RiveraSant'Ana do Livramento. Tesis presentada para la obtención del título de Doctor en Ciencias Sociales, Universidade Estadual de Campinas, Campinas, Brasil.

De Martino-Bermúdez, M. (2012). Primer Informe de Avance del Proyecto Estudio comparado del Programas de Transferencia de Renta Condicionada en UruguayArgentina y Brasil. Informe presentado en la Segunda Misión de Trabajo realizada en abril de 2012 en Montevideo, Uruguay.
De Martino-Bermúdez, M. (2013a). Informe de Avance del Proyecto Estudio comparado del Programas de Transferencia de Renta Condicionada en Uruguay-Argentina $y$ Brasil. Informe presentado en la Cuarta Misión de Trabajo realizada en septiembre de 2013 en Tandil, Argentina.

De Martino-Bermúdez, M. (2013b). Género y Trabajo Social. Algunos desafíos. Cuhso, 23 (1), pp. 109-125.

De Martino-Bermúdez, M. (2014). Políticas Sociales, Familias y profesiones asistenciales. Algunos puntos actuales de tensión. Parentalidades y Cambios Familiares. Enfoques teóricos y prácticos, (pp. 292- 303). Montevideo: Inau.

De Martino-Bermúdez, M. \& Morás, L. (2007). Sobrecercaníasy distancias. Problemáticas vinculadas a la fragmentación social en el Uruguay actual. Montevideo: Cruz del Sur.

Dubet, F. (2006). El declive de la institución. Profesiones, sujetos e individuos ante la reforma del Estado. Barcelona: Gedisa.

Dubet, F. (2013). El trabajo de las sociedades. Buenos Aires: Amorrortu.

Duschatzky, S. \& Corea, C. (2002). Chicos en banda. Los caminos de la subjetividad en el declive de las instituciones. Buenos Aires: Paidós.

Feijó, M. \& Bottinelli, L. (2014). ¿Quiénes son los jóvenes ni-ni? La categoría "nini" en debate. Recuperado de: http:// www.nuevatierra.org.ar/blog/2014/05/06/ jovenes-e-inclusionla-categoria-ni-ni-endebate/

Feixa, C.; Molina, F. \& Alsinet, C. (2002). Movimientos juveniles en América Latina. Pachucos, malandros, punketas. Madrid: Ariel.

Fernández, A. (1999). Instituciones Estalladas. Buenos Aires: Eude.

Foucault, M. (2002). Arqueología del saber. Buenos Aires: FCE.

Freud, S. (1973). Nuevas observaciones sobre las psiconeurosis de defensa. Madrid: Biblioteca Nueva.

Freud, S. (1979). Más allá del principio del placer. En S. Freud. Obras completas. Tomo XVIII, (pp. 233-298). Buenos Aires: Amorrortu. 
Freud, S. (1984). Neurosis y sintomatología en la infancia. Barcelona: Paidós.

Freud, S. (1991). Normalidad y patología en la niñez. Barcelona: Paidós.

Freud, S. (1999). La interpretación de los sueños. Madrid: Alianza.

Giorgi, V.; Kaplún, G. \& Morás, L. (2012). La violencia está en los otros. La palabra de los actores educativos. Montevideo: Trilce.

Irigaray, L. (1985). This Sex Which is Not One. New York: Cornell University Press.

Kaplún, G. (2008). ¿Educar ya fue? Culturas Juveniles y Educación. Montevideo: UdelaR, Nordan.

Katzman, R. (2001). Seducidos y abandonados: el aislamiento social de los pobres urbanos. Documentos de Trabajo del Ipes. Versión revisada de un documento presentado en el IV Foro Internacional organizado por el Centro de Análisis y Difusión de Economía Paraguaya (Cadep) en Asunción, 23 y 24 de Noviembre de 2000, Paraguay.

Lindsay, P. \& Norman, D. (1983). Introducción a la psicología cognitiva. Madrid: Tecnos.

Merton, R. (2003). Teoría Social y Estructura Social. Madrid: FCE.

Mitjavila, M. (1998). La externalidad de los discursos contemporáneos sobre la investigación en Trabajo Social. Fronteras, (3), pp. 53-60.

Negrete, R. \& Leyva, G. (2013). Los NiNis en México: una aproximación crítica a su medición. Realidad, Datos y Espacio, $(s / d)$. Recuperado de: http://www.inegi. org.mx/RDE/RDE_08/RDE_08_Art6.html

Perrot, M. (1996). La juventud obrera- Del taller a la fábrica. En G. Levi \& J. C. Schmitt (org.) Historia de los jóvenes. Tomo II. La edad Contemporánea, (pp. 67-95). Madrid: Taurus.

Prensa Latina \& Juventud Rebelde (2015). Más de la mitad de los jóvenes a nivel mundial no estudia ni trabaja. La Habana: Prensa Latina, Juventud Rebelde. [Diario Digital]. Recuperado de: http://www.juventudrebelde.cu/ internacionales/2015-01-16/onu-mas-dela-mitad-de-los-jovenes-a-nivel-mundialno-estudia-ni-trabaja/
Real de Azúa, C. (1990). El impulso y su freno. Montevideo: Arca.

Reguillo, R. (2012). Horizontes fragmentados: una cartografía de los miedos contemporáneos y sus pasiones derivadas. Diálogos de la Comunicación, (s/d). Recuperado de: http://www. dialogosfelafacs.net/wp-content/ uploads/2012/01/75-revista-dialogoshorizontes-fragmentados.pdf

Rodríguez, E. (2004). Políticas y estrategias de inserción laboral y empresarial de jóvenes en América Latina: el desafío de la empleabilidad. Revista Latinoamericana de Ciencias Sociales, Niñez y Juventud, 2 (1), pp. 75-126.

Rofman, R. (ed.) (2014). Hacia un Uruguay más equitativo. Los desafios del sistema de Protección Social. Montevideo: BM. Recuperado de: http://www.worldbank. org/content/dam/Worldbank/document/ LAC/hacia_un_uruguay_mas_equitativo_ web.pdf

Uruguay, Ministerio de Desarrollo SocialMides (2012). Programa Jóvenes en RED. Recuperado de: http://www.mides.gub.uy

Viscardi, N. \& Alonso, N. (2013). Gramáticas de la Convivencia. Un examen a la cotidianeidad escolar y la cultura politica en la Educación Primaria y Media en Uruguay. Montevideo: Convivencia.

Vives, M. (2005). Test Proyectivos: Aplicación al Diagnóstico y al Tratamiento Clínicos. Barcelona: Universitat de Barcelona.

Wacquant, L. (2006). Castigar a los Parias Urbanos. Antipoda (2), pp. 59-66.

Winnicott, D. (1971). Realidad y Juego. Barcelona: Gedisa.

Winnicott, D. (1981a). La agresión en relación con el desarrollo emocional. En D. Winnicott. Escritos de pediatría y psicoanálisis, (pp. 297-313). Barcelona: Laia.

Winnicott, D. (1981b). Objetos y fenómenos transicionales. En D. Winnicott. Escritos de pediatría y psicoanálisis, (pp. 313 -330). Barcelona: Laia.

Yin, R. (1989). Case study research. London: Sage. 